\title{
«Mala fe», «pasado» y «muerte». Una lectura a partir de la filosofía de Jean-Paul Sartre
}

\author{
Ikiru | Akira Kurosawa | 1952 \\ Martín Prestía" \\ Universidad de Buenos Aires (UBA)/CONICET-IIGG, \\ Argentina
}

Recibido: 25 de julio de 2020; aprobado 12 de agosto de 2020

\begin{abstract}
Resumen
La obra cinematográfica de Akira Kurosawa ha sido a menudo analizada a partir de ciertas categorías de la vasta atmósfera o sensibilidad -literaria y filosófica- del «existencialismo». La finitud, la angustia, el absurdo, la autenticidad, la decisión, recorren buena parte de su filmografía. La película Ikiru [Vivir, 1952] es quizá una de sus producciones más elocuentes al respecto. Inspirada en la historia de Tolstói La muerte de Iván Illich, el film de Kurosawa se ubica en los últimos meses de la vida de Kanji Watanabe, Jefe de la Sección de Ciudadanos de Tokio, una oficina de una compleja burocracia estatal que es retratada como inoperante. Su vida cambia de raíz al recibir la noticia de que se halla enfermo de cáncer de estómago y que le resta un año de vida. A partir de entonces, el film mostrará los diversos intentos del protagonista por hallar un sentido a su vida. El propósito del presente artículo es ofrecer una interpretación del film de Akira Kurosawa a partir de algunos conceptos incluidos en L'être et le néant [1943], la obra filosófica fundamental de Jean-Paul Sartre. Se prestará especial atención a la característica noción sartreana de «mala fe», a la relación del para-sí con el «pasado» y al tratamiento que el autor francés hace de la «muerte», en polémica con Martin Heidegger.
\end{abstract}

Palabras Clave: Akira Kurosawa | Jean-Paul Sartre | filosofía francesa | existencialismo | proyecto | muerte

«Bad faith», «past» and «death». A reading based on Jean-Paul Sartre’s philosophy

Abstract

The cinematographic work of Akira Kurosawa has been analyzed from certain categories of that vast literary and philosophical movement that has been called «existentialism». The finitude, the anxiety, the absurd, the authenticity, the decision -typical «existentialist» motives-, run through much of his filmography. On this regard, the film Ikiru [To Live, 1952] is perhaps one of his most eloquent productions. Inspired by Tolstoy's The Death of Ivan Ilych, Kurosawa's work is set in the last months of the life of Kanji Watanabe, Head of the Tokyo Citizens' Section, a minor office of a complex state bureaucracy that the film portrays as inoperative. His life changes at the root when he realizes that he has stomach cancer and has only one year to live. The film will show Watanabe's various attempts to find meaning to his life. The purpose of this article is to offer an interpretation of the film based on some concepts included in L être et le néant [Being and Nothingness, 1943], Jean-Paul Sartre's fundamental philosophical work. I wwill focus on the characteristic Sartrean notion of «bad faith», the relationship between the For-Itself and the "past», and the analysis of «death», in controversy with Martin Heidegger.

Keywords: Akira Kurosawa | Jean-Paul Sartre | french philosophy | existentialism | project | death

\section{Introducción}

La obra cinematográfica de Akira Kurosawa ha sido a menudo analizada a partir de ciertas categorías de esa vasta atmósfera o sensibilidad-literaria y filosófica- que ha sido denominada «existencialismo» ${ }^{1}$. La finitud, la angustia, el absurdo, la autenticidad, la decisión -motivos típicamente «existencialistas»-, recorren buena parte de su filmografía, y algunas de sus producciones han sido vinculadas con la obra de autores como León Tolstói, Fiódor Dostoievsky Albert Camus, Jean-Paul Sartre e, incluso, Martin Heidegger (Bovens, 1999; Churchill, 2012; Gordon, 1997; Prince, 1991; Richie, 1970).

La película Ikiru [Vivir], de 1952, es quizá una de sus producciones más elocuentes al respecto. Ligeramente inspirada en la historia de Tolstói La muerte de Iván Illich ([1886] 2013), la obra de Kurosawa se ubica en los últimos meses de la vida de Kanji Watanabe, interpretado

* martinprestia@gmail.com 
por el emblemático actor japonés Takashi Shimura. Watanabe es el Jefe de la Sección de Ciudadanos de Tokio, una oficina menor de una compleja burocracia estatal que el film retrata como inoperante. Su vida cambia de raíz al recibir la noticia de que se halla enfermo de cáncer de estómago y que le resta, como máximo, un año de vida. A partir de entonces, el film mostrará los diversos intentos del protagonista por hallar un sentido a su vida.

Ikiru está dividida en dos partes. La primera cubre las dos terceras partes del film y muestra de forma cronológica los días subsiguientes a que Watanabe se entera de su enfermedad, y la serie de conductas que toma ante su inminente muerte. El tercio restante transcurre en la ceremonia funeraria de Watanabe, en la que los asistentes rinden su homenaje y recuerdan aspectos parciales de los últimos meses de su vida.

En este artículo proponemos una interpretación del film de Kurosawa a partir de algunos desarrollos contenidos en L'être et le néant [El ser y la nada], de JeanPaul Sartre ([1943] 1993). Presentaremos las escenas más importantes del film, intentando indagar en ellas a partir de una serie de conceptos ofrecidos por Sartre en su obra filosófica fundamental. Creemos que una lectura tal permite iluminar ciertos aspectos del film de Kurosawa, de por sí rico en matices y sugestiones. Así, se prestará especial atención al característico concepto sartreano de «mala fe», a la relación del para-sí con el «pasado»-y a la noción de «instante», a ella asociada- y al tratamiento que el autor francés hace de la «muerte», en polémica con Heidegger.

Como es sabido, Sartre plasmó en numerosas obras literarias los tópicos que desarrolló en el plano filosófico-técnico, donde también se valió de ejemplos literarios para ilustrar sus ideas. En ese sentido, mutatis mutandis, el análisis de Ikiru se justifica en tanto y en cuanto, según creemos, ilumina algunas situaciones ónticas de la realidad humana. Más allá de eso, Sartre también ha tenido una relación con el mundo del cine que, sin ser estrecha, no puede desestimarse. El pensador francés participó como guionista de numerosos films -muchos de los cuales jamás vieron la luz-y permitió la adaptación de muchas de sus piezas literarias a la pantalla cinematográfica. Asimismo, en algunas de sus obras teóricas pueden encontrarse referencias al cine como medio, y es conocido el ensayo crítico que le dedicó al clásico Citizen Kane ${ }^{2}$.

Akira Kurosawa finaliza su autobiografía con la siguiente sentencia: "No hay nada que diga más de un creador que su propia obra" (Kurosawa, 1983, p. 189; trad. propia). En boca de Kurosawa esta premisa compe- te, ante todo, a la actividad estética; delimita el ethos de un artista. No obstante, extremando la intuición del realizador japonés, es posible pensarla como el núcleo de toda una antropología filosófica: la existencia humana - esta existencia, o aquella; la tuya, la mía, la del prójimo-se define a partir de sus actos. Para la realidad humana, "ser se reduce a hacer" (Sartre, [1943] 1993, p. 501). Se trata de una de las ideas fundamentales de El ser y la nada y, en general, de toda la filosofía sartreana. En otras palabras, no encontramos una vida humana definida por una «esencia» a la que luego, como por añadidura, le computamos una serie de actos, obras, trayectorias, más o menos prosaicos, más o menos grandes. Antes bien, la existencia humana, una existencia determinada, es esa serie de actos, obras, trayectorias. La existencia es un hacer-se, una tarea: un proyecto.

\section{I. «Mala fe», expectativa de la muerte e irrupción del absurdo.}

Una vida común, ordinaria, banal. Gris. Tal es la vida de Kanji Watanabe, Jefe de la Sección de Ciudadanos de Tokio, un oscuro burócrata que ha pasado sus últimos treinta años entre papeles, cumpliendo y dictando órdenes con arreglo a un plan que él no traza. Es un simple engranaje de la omnímoda maquinaria estatal, automatizada y opaca. Una voz en off nos advierte, desde el comienzo del film, que su «disposición» e «iniciativa» «fueron destruidas por las tareas ingratas y desagradables de la burocracia y el trabajo en la oficina». Watanabe «sólo está matando el tiempo. Pasa de largo por la vida».

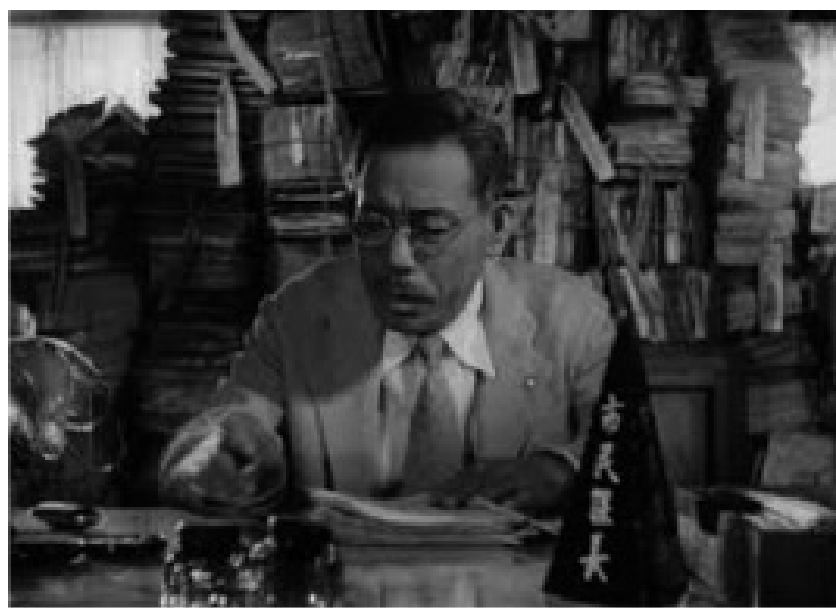

En la primera escena de la película Kurosawa sintetiza, a través de un gesto de Watanabe, la vida del protagonista en su totalidad. Ese gesto refiere a la evasión de 
la responsabilidad, al «retraso de la decisión». Un grupo de mujeres se acerca a la administración pública. Piden por la construcción de un parque en Kuroe-Cho, una barriada popular que se inunda periódicamente, con graves consecuencias sanitarias para los habitantes de la zona. Ante ello, y como funcionario estatal, Watanabe tiene, en un principio, dos opciones: emprender la construcción del parque, o rechazarla. No obstante, en lugar de tomar cualquiera de esas dos vías, delega la decisión en otra instancia gubernamental. Claro que esa es, también, una decisión. La ocupación del protagonista, el entramado profesional en el que se halla inserto, se nos revela -desde prácticamente la primera escena- como un correlato de la realidad humana, que a menudo evade una decisión, des-responsabilizándose.

Esa delegación da pie a una escena en que se pone de manifiesto una compleja y casi kafkiana burocracia estatal, que en todas sus instancias no hace sino repetir el gesto de Watanabe: se desentiende del problema, delegando. Así, la cámara de Kurosawa nos lleva por un innumerable desfile de dependencias estatales -Sección de Parques, Sanidad Pública, Centro de Salud Pública, Sanidad Medio Ambiental, entre otras-, hasta regresar al punto de partida: la oficina de Watanabe. Sólo que esta vez él se halla ausente, por lo que el grupo de mujeres puede elevar un pedido y dejar constancia escrita de que han reclamado por una solución al anegamiento de Kuroe-Cho.

En la siguiente escena, Watanabe se entera de su enfermedad y de su estado terminal. Kurosawa presenta el episodio con maestría, pues no es el personal del hospital quien se lo comunica, sino que él lo infiere a partir de una conversación con otro paciente que aguarda, como él, a ser atendido. Los médicos, de hecho, se lo ocultan, aún ante su insistencia; también ellos evaden, en cierto sentido, su responsabilidad.

Cuando Watanabe abandona la habitación, los dos médicos y la enfermera que lo atendieron dialogan. Afirman lo que el espectador y el propio protagonista ya saben: que le restan unos pocos meses de vida. En la conversación, el médico principal lanza a la enfermera una pregunta que el espectador no puede evadir: "Si solo te quedasen seis meses de vida como a ese paciente, ¿qué harías?". Ante esa interrogación la enfermera responde, un tanto irónica, que "bay veneno en el estante". Introduce con ello la cuestión del suicidio, que volverá algunas escenas más tarde, cuando Watanabe revele su enfermedad al personaje del escritor y le confiese que ha pensado, fugazmente, en acabar con su vida. Watanabe está furioso consigo mismo, pero ha descartado esa opción. Aca- bará por decir al escritor que "No puedo morirme. No sé para qué he vivido todos estos años". La expectativa de la muerte inminente despierta en el protagonista la preocupación por el sentido de la vida humana, de $s u$ vida.

Digámoslo desde un comienzo: la cuestión de la «muerte» no tiene en Sartre el peso ontológico que le ha dado, por ejemplo, Heidegger. Es más, el francés critica la concepción heideggeriana de la muerte, en luminosos pasajes en los que también apunta algunas notas en torno al suicidio y sobre los que volveré en el cuarto apartado del presente trabajo. No obstante, y más allá de que las acciones presentadas en Ikiru sean posibilitadas por la expectativa de la muerte inminente, el «no saber para qué» que el protagonista balbucea trasunta una temible sospecha que es, después de todo, ajena a aquella expectativa: la falta de sentido de la vida, su absurdo. Al mismo tiempo, esas palabras vislumbran una segunda cuestión, quizás más temible: es necesario asumir la responsabilidad de los propios actos, esto es, la absoluta libertad del ser humano en la elección. No sé para qué he vivido, pero esa es $m i$ vida, y la de nadie más. Puedo buscar excusas, aducir pretextos y encontrar razones; puedo desplegar complejos mecanismos de autoengaño y culpar a la suerte, al destino o a una serie de circunstancias que «se me impuso» y de las que «no pude rehuir»; puedo, en fin, desentenderme completamente de mi responsabilidad, entregándome por entero al engranaje del «mundo objetivo». Watanabe lo hará en numerosas oportunidades, no sólo en el ámbito laboral, sino también en relación a su vida personal y afectiva. Hemos alcanzado, así, un terreno común con la preocupación sartreana.

A este estado de cosas en que la conciencia «se miente a sí misma», Sartre lo llama «mala fe». Se trata de una mentira que es radicalmente distinta a la que se lanza al otro, pues en esta última "el mentiroso está completamente al corriente de la verdad que oculta” (1993, p. 82). La mala fe, en cambio, "pertenece a ese género de estructuras psíquicas que podrían llamarse «metaestables»" (p. 84), y que descansa en la estructura ontológica de la realidad humana, que «es lo que no es y no es lo que es». La mala fe no es "una decisión reflexiva y voluntaria” sino, antes bien, "una espontánea determinación de nuestro ser", una estructura inmediata que el para-sí puede adoptar frente a su ser: "[u]no se pone de mala fe como quien se duerme, y se es de mala fe como quien sueña. Una vez realizado este modo de ser, es tan difícil salir de él como despertarse" (p. 102; énfasis original). Más aún: para Sartre la mala fe "puede ser el aspecto normal de la vida para gran número de personas", lo que no 
impide que "se tengan bruscos despertares de cinismo o de buena fe" (p. 84).

Volvamos al film para intentar ilustrar una de las formas de la mala fe, aquella que se basa en "la ambigüedad nihilizadora de los tres ek-stasis temporales" (Sartre, 1993, p. 92) $)^{4}$ Tras recibir la noticia de su enfermedad, Watanabe sale a la calle en dirección a su hogar. Ya de regreso, enciende una vela para el altar de su difunta esposa. La perspectiva de su deceso próximo conmina al protagonista a echar una mirada retrospectiva sobre su vida y sobre los acontecimientos y decisiones fundamentales que trazaron su particular curva: su temprana viudez, su devoción por su hijo, su trabajo mediocre pero suficiente, al que no dejó de asistir ni un solo día en los últimos treinta años. Todo ello cobra ahora otro cariz. «¿Soy yo, aquello, aún?» parece preguntar el rostro extraviado de Watanabe. Kurosawa introduce con ello la cuestión del pasado, su peso muerto: "el pasado como esencia que el para-sí era” (Sartre, 1993, p. 512) y que, a la postre, habrá de nihilizar, como veremos en los próximos apartados. Watanabe es ese pasado, pero lo es en función de su proyecto, ratificado a cada instante. "Yo solo", dice Sartre, "puedo decidir en cada momento sobre el alcance del pasado, pero no discutiendo, deliberando y apreciando en cada caso la importancia de tal o cual acontecimiento anterior, sino que, pro-yectándome hacia mis objetivos, salvo el pasado conmigo y decido acerca de su significación por medio de la acción” (1993, p. 523; énfasis original). Y precisa: "si la libertad es elección de un fin en función del pasado, el pasado, recíprocamente, no es lo que es sino con relación al fin elegido" (1993, p. 522).

Entiéndase bien: no se pone en duda con ello el "hecho bruto" acontecido en el pasado, su "elemento inmutable" (1993, p. 522). La esposa de Watanabe ha muerto. Pero la significación de tal pasado se da a partir de lo que el proyecto libremente elegido -el futuro- ilumina. El protagonista de Ikiru ha trazado un proyecto de «hombre viudo que no volverá a casarse para favorecer a su hijo». Hace caso omiso a los consejos de su hermano y cuñada que, tal y como se nos presenta en el recuerdo de Watanabe, le recomiendan que se busque otra mujer. Más aún: podrían bosquejarse unos breves apuntes de psicoanálisis existencial para mostrar cómo el resto de sus proyectos puede reconducirse al de «viudez-para-el-hijo»: la asistencia perfecta a su trabajo, su carácter austero y frugal, su condición de abstemio. El para-sí es libre elección y, como tal, una totalidad: "cada uno de sus actos, el más insignificante como el más considerable, traduce esa elección y emana de ella" (Sartre, 1993, p.
621). Pero Watanabe no puede dar cuenta de su proyecto como libre elección del para-sí; no puede manifestar ante su propia conciencia que habría podido emprender una infinidad de proyectos alternativos ante la situación configurada por su viudez. En ese sentido, promediando la película tendrá un diálogo con Yoko, su subordinada en la dependencia estatal, que será del todo revelador. Ella le confiesa que le había puesto un apodo: "La Momia", a lo que él responde: "El motivo por el cual me convertí en momia... fue todo por el bien de mi bijo. Sin embargo, él no me lo agradece". Yoko lo rebate: "¿Pero usted no puede culpar por eso a su bijo, no le parece? A menos que él le haya pedido que se convirtiera en una momia ".

Watanabe es de mala fe en el modo en que el para-sí afirma que es lo que ha sido, de una vez y para siempre; su conducta es la del "hombre que se detiene deliberadamente en un período de su vida y se niega a tomar en consideración los cambios ulteriores" (Sartre, 1993, p. 92). Al fijarse en un curso de acción dado en el pasado -y que acontecería de manera externa e irrevocable, provocado por la muerte de su esposa-, Watanabe presenta su vida como unívocamente determinada, y sus acciones como necesarias. En la «mala fe», la conciencia encuentra sosiego ante la angustia provocada por la libertad.

\section{Primera negación del pasado: disfrute}

Ante la expectativa de su inminente muerte, Watanabe, prácticamente un abstemio, se emborracha lastimosamente en una casa de comidas y hace un amigo por esa noche, un «escritor de novelas baratas»-como él mismo se define- al que confiesa su enfermedad, y ante el que afirma: "Bebo este sake tan caro como protesta a la vida que be llevado hasta abora". Al escritor lo encandila la figura de Watanabe. Le parece encomiable el cambio brusco por él producido: "Usted ha llevado una vida de esclavo y ahora quiere mandar sobre su vida”. Ensaya una suerte de imperativo: "El deber de todo hombre es disfrutar de la vida. Los hombres debemos sentir lujuria por la vida". El primer momento de la peripecia del protagonista está signado por la figura de ese escritor, un bohemio con suficiente dinero como para encargarse de los gastos de la noche, y que lo llevará a entregarse a los placeres: alcohol, baile, mujeres; formas que de pronto hacen sentido para Watanabe. "Seré un Mefistófeles virtuoso que no exige recompensa", expresa el escritor, y abre las puertas de una porción del mundo de la que Watanabe se había sustraído. 
La maestría narrativa de Kurosawa se muestra en todo su esplendor al ofrecer al espectador una sucesión de innumerables escenas de la noche japonesa en la que el automatismo formal de la filmación replica el automatismo existencial de los personajes en pantalla. Como en un contrapunto armonioso con la secuencia en que fuimos conducidos por las distintas dependencias de la burocracia estatal, esta vez paseamos junto a los personajes por calles céntricas abarrotadas, clubes nocturnos, bares y cafés. La vertiginosa presentación de escenas desemboca en uno de los clímax del film, el momento en que Watanabe desgarradamente entona, en un café cantante al que los personajes han llegado, la bella y nostálgica canción popular japonesa La vida es breve. Kurosawa construye la escena de manera orgánica, y Takashi Shimura encarna espléndidamente ese momento de súbita iluminación. La visceral interpretación de Shimura retrata a un hombre que ha vislumbrado, siquiera fugazmente, el absurdo.

La alegría irreflexiva de la juerga nocturna acaba cuando las primeras luces del día asoman. A pesar de su copa áurea, el «árbol de la vida» que este Mefistófeles ha sembrado para Watanabe tiene las raíces podridas. $\mathrm{Al}$ encontrarse a solas con sí mismo, Watanabe vuelve a encontrarse a solas con la perspectiva de su muerte inminente. Descartada la posibilidad de una evasión en los placeres, buscará una emoción más duradera, una emoción que trascienda lo efímero.

El protagonista entabla una relación con una empleada suya, Yoko, una muchacha mucho más joven que él que quiere renunciar a su trabajo. La labor administrativa es rutinaria, banal, tediosa. Yoko se aburre, quiere «algo nuevo». Quiere disfrutar, sí, pero no como quien busca una evasión, sino como quien celebra la alegría de vivir. En su boca podríamos poner la célebre sentencia nietzscheana: “¿Era esto la vida? ¡Bien! ¡Otra vez!” (Nietzsche, 1979, p. 225). La figura de Yoko contrasta fuertemente con la del escritor de novelas. Éste no es más que un apesadumbrado bohemio, un intelectual que toma somníferos para poder dormir y ahoga su spleen en alcohol. Yoko, en cambio, es una chica humilde: lleva las medias rotas y vive en una casa en la que tres familias comparten dos habitaciones. La figura de la joven que posibilita el segundo momento de la peripecia de Watanabe es la de una trabajadora que goza y disfruta de los pequeños placeres de la vida como alivio y recompensa a la dura y esforzada labor cotidiana.

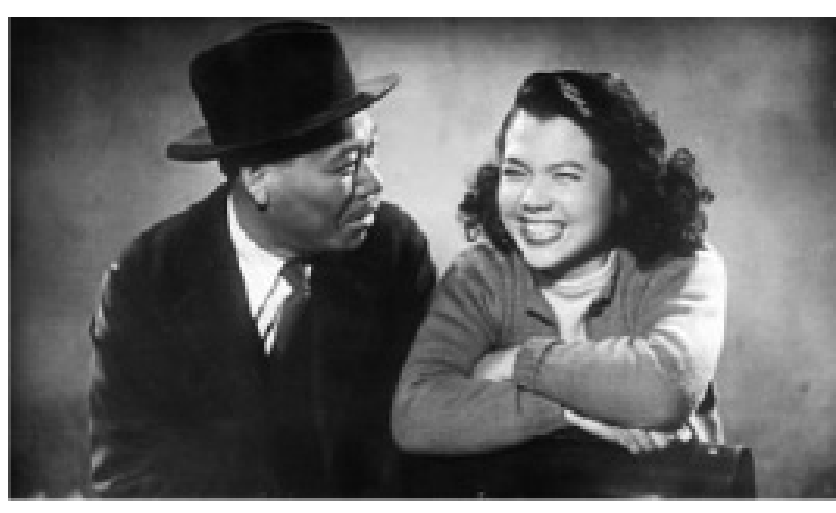

Tras firmar los papeles que habilitan su renuncia, Watanabe ofrece acompañarla a su casa, a partir de lo cual terminarán pasando el día juntos. La lleva de compras y le obsequia un par de medias nuevo; luego almuerzan, pasean por un parque de diversiones, meriendan, van al cine y, finalmente, cenan. Este será el primero de varios encuentros que, en principio, no parecen reflejar interés erótico ni deseo sexual, si bien la familia del protagonista y la joven terminan por sospecharlo. Watanabe no desea a la muchacha: desea su vitalidad, desea su deseo de vida. Quiere que le enseñe a vivir jovialmente. Ella, a su vez, no tiene por él interés erótico de ningún tipo. Al cabo de un tiempo, no lo considera siquiera un amigo. El automatismo de la labor burocrática ha hecho carne en Watanabe, quien aparece ante los ojos de la joven como una mera extensión de su trabajo. "¿Para qué iremos a pasear?”, pregunta Yoko en el último de sus encuentros. "Luego iremos a una confitería y más tarde a comer sushi o unos tallarines, ¿no? Dime, ¿de qué sirve que repitamos todo eso?”. Quien fuera su Jefe acaba, también, por aburrirla.

En los dos primeros momentos del film, esto es, su peripecia con el escritor y su fugaz relación con Yoko, Watanabe nihiliza su pasado, o al menos una parte de él. En primer lugar, porque decide faltar a su trabajo. Resigna, así, su asistencia perfecta durante casi 30 años y, con ello, su proyecto de «empleado-récord». Luego, en su peripecia con el escritor, Watanabe niega en cierto sentido su proyecto de "padre-sacrificado", su carácter abstemio y diurno, su vida frugal. Asimismo, al gastar una importante suma de dinero con la muchacha -lo cual le traerá la queja de su hijo, y un pedido de aclarar las cuentas, bajo sospecha de que su padre tiene una amante que quiere aprovecharse de él-, niega su proyecto de «hombre-ahorrador», que de algún modo daba sustento y se interrelacionaba con otras dimensiones de su proyecto -frugalidad y viudez-, siempre de cara a una suerte de «entrega» hacia su hijo. 
No obstante, si bien con esos dos momentos Watanabe niega irremediablemente una parte del pasado que lleva a cuestas, continúa, en cierto sentido, evadiendo una decisión. En efecto, lo que unifica ambos momentos de su peripecia es que el protagonista transfiere la decisión a Otro: al escritor, primero, a quien le pide que lo lleve de juerga; a la jovencita, después, a quien consiente en salidas, paseos, comidas. En ambas instancias, Watanabe es de mala fe, es un objeto para los otros. Kurosawa desliza esta cuestión al retratar al protagonista como una persona incómoda: incluso en compañía de Yoko, con quien parece estar más a gusto que con el escritor, el rostro de «felicidad» momentáneamente se quiebra, y Watanabe vuelve a agachar la cabeza y encorvar los hombros en gesto melancólico.

Es en la conversación de «ruptura» con la joven que el protagonista cree encontrar un sentido para los escasos momentos de vida que le quedan. Yoko no sabe cómo vive: "Yo solo como y trabajo. De verdad. Sólo hago juguetes como este", dice, y le muestra un pequeño conejito que fabrica en su nuevo empleo. "Pero me divierto. Es como si todos los bebés de Japón fueran amigos míos. ¿ Por qué no hace usted algo parecido?”. Asistimos, con ello, a un momento de súbita iluminación o epifanía del personaje, que el rostro de Takashi Shimura retrata con justeza. De cara hacia la muerte, Watanabe decide hacer algo valioso con su trabajo, algo que pueda impactar en la vida de sus prójimos. Se vive junto a otros, pero también se muere junto a otros.

\section{Segunda negación del pasado: nuevo proyecto y asunción de la libertad}

Al describir la unidad ek-stática del para-sí, la temporalización de la conciencia, Sartre explica que "no hay una sucesión de instantes separados por nadas" sino "cierta extensión finita de duración concreta y continua" (1993, p. 491). Ese continuo temporal se despliega a partir de la elección, que nihiliza un aspecto del para-sí haciendo que "un futuro venga a anunciarnos lo que somos confiriendo un sentido a nuestro pasado". De ese modo, Sartre concluye que "libertad, elección, nihilización, temporalización son una y la misma cosa” (p. 491).

No obstante, el pensador francés aclara inmediatamente que "el instante no es una vana invención de los filósofos", sino aquello que se produce en el momento en que "ciertos procesos surgen sobre el desmoronamiento de procesos anteriores" (Sartre, 1993, p. 491; énfasis ori- ginal). Más aún: el instante es "[u]n comienzo que se da como fin de un proyecto anterior", "lo que se produce en el caso de una modificación radical de nuestro proyecto fundamental" (1993, p. 492). En ese sentido, en la conversación entre Watanabe y Yoko, Kurosawa retrata el instante en que su proyecto -que venía siendo puesto en duda- se hunde completamente y del cual surge uno nuevo.

En tanto y en cuanto la conciencia es libre, tiene en todo momento "la posibilidad de poner como objeto" el pasado inmediato (Sartre, 1993, p. 493). En otras palabras, el para-sí está "perpetuamente amenazado por el instante" (p. 491), pues el para-sí es radicalmente libertad y todas sus elecciones son, en ese sentido, «absurdas» (p. 505). Como explica Sartre, "es imposible que esa elección [la que configura un nuevo proyecto] no se determine en conexión con el pasado que ella ha de ser. Hasta es, por principio, decisión de captar como pasado la elección a la cual sustituye" (p. 492). De ese modo,

con la nueva elección, la conciencia pone su propio pasado como objeto, es decir, lo aprecia y toma sus notas con respecto a él. Este acto de objetivación del pasado inmediato se identifica con la nueva elección de otros fines: contribuye a hacer brotar el instante como quiebra nihilizadora de la temporalización. (p. 493; énfasis original)

Esa nueva elección se presenta, de algún modo, «transparente» al para-sí: Watanabe reniega expresamente de su comodidad de burócrata y apunta a utilizar los medios que tiene a su alcance para «hacer algo» a partir de ellos: "Podré hacer algo allí si realmente estoy decidido a bacerlo". El rostro expresivo de Takashi Shimura al pronunciar esa frase -de un gesto, en definitiva, inaprensible- se aviene con la poética descripción sartreana de aquellos instantes en que se producen las «conversiones» de distinto orden "que me hacen metamorfosear totalmente mi proyecto original" y que, sin haber sido "estudiadas por los filósofos, han inspirado a menudo, en cambio, a los literatos":

[se trata de] instantes extraordinarios y maravillosos, en que el proyecto anterior se hunde en el pasado a la luz de un proyecto nuevo que surge sobre las ruinas de aquél y que no hace aún sino esbozarse, instantes en los que la humillación, la angustia, la alegría, la desesperación se alían estrechamente, en los que soltamos para asir y asimos para soltar, han podido a menudo dar la imagen más clara y conmovedora de nuestra libertad. (Sartre, 1993, p. 501)

En ese instante despunta el tercer y último momento de la peripecia de nuestro protagonista. Watanabe decide llevar adelante la construcción de un parque en el terreno anegado de Kuroe-Cho, que se había difuminado hacia el comienzo del film, en la sucesión interminable de ins- 
tancias burocráticas que permitían aplazar una decisión.

Tras mostrar los primeros pasos del protagonista en dirección a la construcción del parque, la cinta hace un corte abrupto. Nos encontramos, de pronto, en el funeral de Watanabe. La voz en off del comienzo comunica al espectador que han pasado cinco meses; la cámara enfoca un retrato del difunto encuadrado por arreglos florales. Restan aún cincuenta minutos de film. Cincuenta minutos extraordinarios, que transcurren en la ceremonia de despedida celebrada para el protagonista, con breves flashbacks que van completando momentos destacados de los últimos meses de su vida, en que el proyecto de construcción del parque consumió toda su atención.

Tres grandes grupos de personajes se hallan presentes al comienzo de la ceremonia. Los familiares, que atienden a los asistentes y permanecerán durante toda la velada; el Primer Teniente de Alcalde y su séquito de burócratas -esto es, los superiores del difunto-, que abandonarán la sala a los pocos minutos de comenzada la escena; y, finalmente, una serie de funcionarios públicos entre los que se cuentan subordinados de Watanabe y Jefes de otras secciones, esto es, funcionarios de su mismo rango, junto con sus propios empleados.

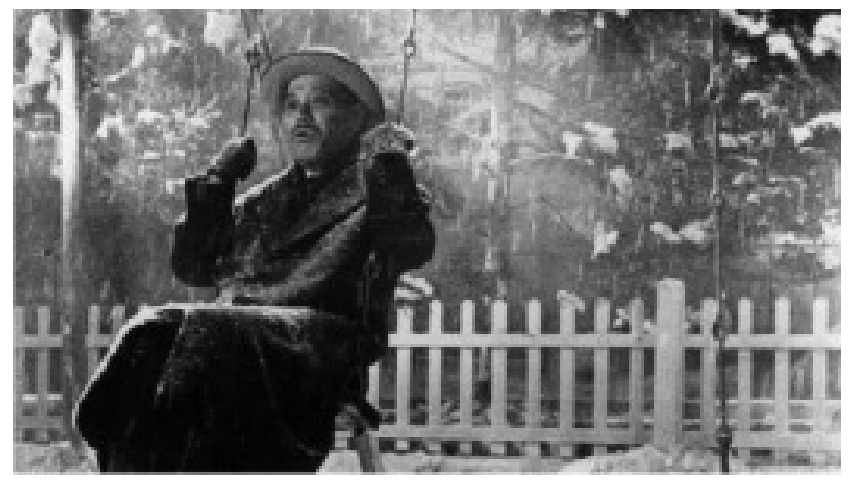

En un primer momento, un grupo de periodistas llega al lugar en que Watanabe está siendo velado. Permanecen sin ingresar al recinto, pero piden hablar con el Primer Teniente de Alcalde. Le comunican, un tanto irónicamente, que un rumor de queja se esparce entre la barriada de Kuroe-Cho. El espectador se entera de que la construcción del parque se ha concretado, y que esa queja se debe a que, aunque oficialmente el mérito de la obra pública recae sobre la Sección de Parques, la población está convencida - lo ha visto con sus propios ojos- de que fue Watanabe quien la llevó adelante. Al no nombrarlo en el discurso de inauguración, cuando el protagonista del film aún vivía, los vecinos consideran que se ha cometido una injusticia, y que esa inauguración no fue más que una muestra de mero oportunismo electoral. Los periodistas agregan que, en el contexto de un «sentimiento de apego generalizado hacia su persona», la muerte de Watanabe, que tuvo lugar en el propio parque durante la helada noche anterior, ha sido interpretada como «una protesta silenciosa contra el gobierno de la ciudad», una suerte de sacrificio o inmolación que buscaría revelar los resortes ocultos de la maquinaria gubernamental. El Primer Teniente de Alcalde ridiculiza esa interpretación, y aclara prontamente a la prensa que "La causa de su muerte no es el frío. Tenía cáncer. Falleció repentinamente, cuando menos se lo esperaba".

Cuando el Primer Teniente de Alcalde regresa a la habitación, se abre una conversación que gira en torno al grado de responsabilidad de Watanabe en la construcción del parque. Aquel procura desligarlo de la obra: como Jefe de la Sección de Ciudadanos, el difunto no tenía ninguna incidencia, a diferencia del Jefe de Parques, que se halla presente y a quien corresponderían los laureles.

Un cuarto grupo de personas llega a la ceremonia: se trata de las mujeres que habían pedido por la solución del anegamiento periódico de su barriada. Contrariamente a la opinión del resto de los burócratas, ellas consideran a Watanabe el responsable de la construcción del parque. Presentan sus respetos al difunto, con incienso y ofrendas. Están visiblemente compungidas, a algunas les cuesta contener el llanto. El espectador parece asistir a los gestos de devoción que se tienen por un héroe, o por un santo laico.

Las mujeres acaban por retirarse, y las siguen el Primer Teniente de Alcalde y su séquito. Inmediatamente después, uno de los subordinados del difunto opina, intempestivo: "Fue el Señor Watanabe quien construyó ese parque!". Tras una negativa generalizada, la opinión suscita en los presentes una serie de reconsideraciones sobre las últimas acciones de quien fuera su Jefe y colega. A partir de entonces, el film se estructura a través del recurso narrativo del flashback, en que cada asistente presenta una porción de la historia, según lo que pudo conocer. Se nos presentan escenas sucesivas en que el protagonista: ordena estudiar el terreno anegado; insiste a varios jefes de otras secciones burocráticas para que acompañen su decisión; visita la Sección de Asuntos Generales y tiene un altercado con el Primer Teniente de Alcalde; supervisa la construcción del Parque y sufre una caída en la que es socorrido por las mujeres; $y$, finalmente, escucha las amenazas, sin dejarse amedrentar, de un grupo que tiene interés en construir una taberna en el mismo predio. Con ello se irán develando, ante los asistentes al velorio, no 
sólo los alcances de la participación de Watanabe en la construcción del parque, sino también que sabía de su enfermedad.

Finalmente, uno de los empleados repite la evasión y la «mala fe»: "En la Administración no se puede bacer nada. Si se te ocurre algo te tachan de radical. Así que lo unico que puedes hacer es fingir que haces algo". Sin embargo, al cabo de una serie de discusiones, los asistentes a la ceremonia de despedida acaban por ponerse de acuerdo: Watanabe ha construido el parque; su decisión se sobrepuso a los múltiples impedimentos administrativos. ";Vamos a trabajar duro, con el mismo espiritu que Watanabe! ¡No permitiremos que su muerte haya sido en vano!", exclama otros de sus subordinados. La vida de Watanabe es ejemplar, y a partir de entonces hay que vivir a la altura de las exigencias que plantea el modelo.

\section{La muerte y los otros}

La muerte ha sido, tácitamente, el tema que ha motorizado todas las acciones retratadas por el film. Es a raíz de conocer su inminente muerte que Watanabe rompe con algunos aspectos de su pasado y se lanza hacia nuevas posibilidades.

Como adelanté en el primer apartado, a diferencia de Heidegger, en quien Sartre se ha inspirado largamente en relación a otras dimensiones del análisis de la realidad humana, y para quien la muerte tiene un lugar central en la estructura ontológica de la existencia -a partir de la «resolución anticipatoria»: el Dasein es Sein-zum-Tode, ser-para-la-muerte-, para el autor francés, en cambio, la anticipación de la muerte no juega ningún papel importante en relación al proyecto. Sartre aborda el tema lateralmente en varios pasajes de El ser y la nada, aunque lo examina en profundidad -si bien de manera breve- en el apartado "Mi muerte", del primer capítulo de la cuarta parte. La indagación en el tema de la muerte se realiza en el marco de sus consideraciones en torno a las relaciones entre libertad y facticidad, esto es, en su análisis de la «situación».

Según Sartre, uno de los principales errores de Heidegger radica en su identificación entre "muerte" y "finitud". Contra lo afirmado por el autor de Sein und Zeit, Sartre argumenta que sólo la segunda es una estructura ontológica del Dasein o para-sí (1993, p. 569). "No hay ningún lugar para la muerte en el para-sí”, advierte Sartre, y continúa: [el para-sí] no puede ni esperarla, ni realizarla, ni proyectarse hacia ella; la muerte no es en modo alguno el fundamento de su finitud y, de modo general, no puede ni ser fundada desde adentro como proyecto de la libertad original ni ser recibida de afuera como una cualidad por el para-sí. (p. 569)

Asimismo, siempre según Sartre, no podemos esperar la muerte pues ella es del todo azarosa e indeterminada; antes bien, con la muerte debemos contar. Introduce, con ello, una distinción entre muerte como hecho contingente y como condición mortal, una distinción que se recorta sobre el fondo de la diferencia óntico/ontológica. $\mathrm{Al}$ negar a la muerte un lugar destacado en la estructura ontológica del para-sí, al negar el carácter de posibilidad que le otorga Heidegger -"la muerte no es mi posibilidad de no realizar más la presencia en el mundo", dirá Sartre, "sino una aniquilación siempre posible de mis posibles, que está fuera de mis posibilidades" (p. 560; énfasis original)-, Sartre la coloca como un hecho que escapa al para-sí por principio, y que pertenece, como el nacimiento, a la facticidad (p. 568).

Podemos esperar una muerte determinada, pero no la muerte (Sartre, 1993, p. 557). Y, aún en el caso de que sepamos que nuestra muerte será una muerte -Sartre utiliza el ejemplo de un condenado que espera su ejecución y el del que aguarda el desenlace de una enfermedad (p. 558), bajo el cual podríamos incluir el caso retratado en Ikiru-, "lo propio de la muerte es que puede siempre sorprender antes del plazo a aquellos que la esperan para tal o cual fecha" (p. 559). La muerte, como la vida, es considerada por Sartre un absurdo.

El proyecto libremente elegido por el para-sí que asume su condición mortal no tiene, para Sartre, "una diferencia de fondo" con aquel que se establece en relación a la libertad de otro para-sí, de otra conciencia (p. 570). La muerte es "el reverso ineluctable" de cada uno de mis proyectos pero, precisamente porque no puedo esperar, ni realizar, ni armarme contra la muerte, ella "no me merma", no limita la libertad del para-sí (p. 570; énfasis original). Más aún, al reestablecer la diferencia entre muerte y finitud, que Heidegger habría confundido, Sartre llega a decir que, aun siendo inmortal, el ente humano seguiría siendo finito, pues seguiría eligiendo un posible entre otros, esto es, un proyecto que excluiría, en el mismo acto de la elección, a otros proyectos, siempre infinitos (p. 569).

En el capítulo siguiente de El ser y la nada, centrado en el psicoanálisis existencial, se ve con claridad que la meditación sartreana en torno a la muerte pretende, en relación a Heidegger, reubicar las modalidades del $D a$ sein de cara a su condición mortal -esto es, "la angustia 
ante la muerte, la decisión resuelta o la huida a la inautenticidad" (Sartre, 1993, p. 587)- sobre la base de una elección o proyecto originario, que es por principio del todo independiente de la muerte. Así, Sartre reclama que hay que "ir más allá de los resultados de la hermenéutica heideggeriana", pues esas modalidades del Dasein "sólo será posible comprenderlas [] sobre el fundamento de un proyecto primero de vivir, es decir, sobre una elección originaria de nuestro ser" (1993, p. 587; énfasis original). Al ensayar el análisis de una trayectoria individual concreta, la elucidación de ese proyecto fundamental "no debe remitir [ ] a ningún otro, y debe ser concebido por sí” (1993, p. 587). El proyecto fundamental u originario "no puede sino apuntar a su propio ser" (1993, p. 588; énfasis original). Con ello reafirma la separación tajante entre muerte y finitud.

No obstante, la argumentación sartreana parece proporcionar matices al apuntar, siquiera escuetamente, algunas muertes concretas. En efecto, Sartre admite una ocasión en que la muerte, ya no como condición del para-sí-el «contar con» ella- sino como hecho contingente -«la espera de una muerte»-intercede, se interrelaciona, con el proyecto. Citamos in extenso:

hay una considerable diferencia de cualidad entre la muerte en el límite de la vejez y la muerte súbita que nos aniquila en la madurez o en la juventud. Esperar la primera es aceptar que la vida sea una empresa limitada, una manera entre otras de elegir la finitud y de elegir nuestros fines sobre el fundamento de la finitud. Esperar la segunda sería esperar que mi vida fuese fallida. Si sólo existieran muertes por vejez (o por condena explícita), podría esperar (aguardar) mi muerte. Pero, precisamente, lo propio de la muerte es que puede siempre sorprender antes del plazo a aquellos que la esperan para tal o cual fecha. (Sartre, 1993, p. 559)

El para-sí que espera su muerte por vejez se asemeja, desde cierto punto de vista, a aquel que está condenado a ejecución y a aquel que tiene una enfermedad terminal: de algún modo, todos ellos esperan una muerte. En el caso del condenado, no obstante, habría que señalar que innumerables acontecimientos pueden torcer el rumbo de su trayectoria vital, salvándolo de esa muerte: desde un repentino cambio en las leyes que derogue la pena capital, a la aparición de nuevas evidencias que prueben que en verdad -tal y como siempre había afirmado- era inocente, hasta un motín que le permita escapar de la cárcel; pasando por un levantamiento revolucionario que libere a todos los cautivos o una declaración de guerra que necesite movilizar incluso a los condenados a la pena máxima, ya al frente, ya a la producción. En contraposición, el caso de una enfermedad terminal como la retratada en Ikiru, de la que se sabe no existe una cura en el estado del conocimiento científico actual, sería más homologable, en los términos planteados por Sartre, al de la vejez. Habría que volver a decir aquí que esa muerte sigue siendo, después de todo, inesperable: el para-sí puede estar enfermo o haber sobrepasado la expectativa de vida promedio $\mathrm{y}$, no obstante, morir en un accidente violento -de igual modo que el sentenciado a una ejecución puede morir a causa de "una epidemia de gripe española” (1993, p. 556). Al mismo tiempo, la muerte no limitaría la libertad tampoco en esas ocasiones: el condenado a muerte, tanto como el enfermo terminal, eligen, en cierto modo, su muerte -por ejemplo, al no suicidarse.

$\mathrm{Y}$, sin embargo, la espera de una muerte -por más que no se cumpla, a la postre, esa muerte- no puede pasar desapercibida al para-sí, no puede serle indiferente, y a ello parece remitir Sartre al mentar la diferencia cualitativa que habría en esos casos, apuntada en el párrafo citado algunas líneas más arriba. Sartre no da mayores especificaciones de esa diferencia de "cualidad", ni el modo en que la "vida" -esto es, el proyecto- se ve "limitado"; tampoco abunda en la formulación, algo enigmática, de en qué consistiría "esa manera entre otras de elegir la finitud". El hecho de la muerte -siempre inesperable e indeterminado pero a sabiendas próximo, inminente- es reabsorbido por el para-sí, es integrado en el proyecto, de un modo que no puede integrarse, según Sartre, la condición mortal. Sartre no avanza por esa vía. Pero quizá podamos apuntar, a modo de tentativa, que, si queremos admitir su crítica a Heidegger, y desvincular la muerte del proyecto, debamos incluir algunas situaciones ónticas en que la muerte -una muerte- es esperable $y$, como tal, integrada en el proyecto. Incluso, que pueda modificar la elección original, que "puede ser siempre revocada por el sujeto” (Sartre, 1993, p. 596; énfasis original). La trayectoria vital de Watanabe, signada por la expectativa de la muerte inminente, podría ser abordada desde esta perspectiva.

Llegados a este punto, sin embargo, podría cuestionarse la elección del pensamiento sartreano para un análisis del film Ikiru. Pues, si bien ha iluminado algunos de sus aspectos -como la vida del protagonista, analizada a partir de la noción de «mala fe» y de la relación del para-sí con el pasado-, dejaría en penumbra otras dimensiones, quizás más importantes, desde que el film de Kurosawa se estructura a partir de la expectativa de la muerte inminente, que Sartre, al considerar que la muerte tiene un papel nulo en la estructura ontológica del para-sí, toma únicamente como un caso entre otros. No 
obstante, la concepción sartreana de la muerte tiene otras aristas que se ven reflejadas en el film, particularmente en lo que hace a su análisis desde el punto de vista de sus "significaciones" (Sartre, 1993).

Sartre impugna las concepciones filosóficas y literarias que pretenden ver en la muerte una suerte de «acorde final» o «coronamiento» de una vida. En primer lugar, como hemos visto, porque la muerte como tal -la condición mortal del ente humano- no puede esperarse. Pero, más importante aún, porque por principio la muerte nunca le ocurrirá al para-sí: nunca podrá dar cuenta de ella. La muerte es la única esfera de la facticidad sobre la cual el para-sí no puede "volver sobre sus pasos», no puede otorgar donación de sentido. Una vez he sido alcanzado por la muerte, "[m]i vida entera es, [pero] esto no significa en modo alguno que sea una totalidad armoniosa, sino que [] no puede ya cambiarse por la simple conciencia que tiene de sí misma” (p. 563; énfasis original). En otras palabras, el para-sí no puede responsabilizarse por su muerte, del modo en que lo hace, por caso, con un acontecimiento pretérito. La conciencia puede elegir nacer, pero no morir, pues una vez que ha muerto cae por entero al reino del en-sí. Cesa de ser inconclusión. Desde esta perspectiva, explica Sartre, "aparece claramente la diferencia entre la vida y la muerte: la vida decide acerca de su propio sentido porque está siempre en aplazamiento y posee, por esencia, un poder de autocrítica y autometamorfosis que la hace definirse como «aún no», o ser, si se prefiere, como cambio de lo que ella misma es" (1993, p. 566). Y esto es así, como es evidente, no sólo en aquellos casos en los que la perspectiva de una muerte inminente pudiera ser integrada al proyecto -como en la vejez, o la enfermedad terminal-, sino también en aquellos otros en que la libre elección del para-sí se proyectara hacia la muerte -una muerte-, como hacen el suicida o el mártir. Del suicidio, de hecho, dice Sartre que "[a]l ser un acto de mi vida [ ] requiere a su vez una significación que sólo el porvenir podría conferirle; pero, como es el último acto de mi vida, se niega a sí mismo ese porvenir, y queda así totalmente indeterminado". Así, el suicidio es, para Sartre, "un absurdo que hace naufragar mi vida en el absurdo” (p. 563; énfasis original).

Se ve fácilmente cómo la meditación sartreana de la muerte desde el punto de vista de sus significaciones conduce a indagar en el para-sí como ser-para-otros. Pues si yo no puedo otorgar sentido a mi trayectoria vital, ahora cerrada para siempre, esa donación de sentido viene dada por los otros. Como la «vida viva», la «vida muerta» tampoco cesa de cambiar, "pero no se hace, sino que es hecha" (Sartre, 1993, p. 566; énfasis original). La muerte "da la victoria final al punto de vista del Otro", "confiere un sentido desde afuera a todo cuanto viví como subjetividad; reasume toda esa subjetividad que, mientras «vivía», se defendía contra la exteriorización, y la priva de todo su sentido subjetivo para entregarla a cualquier significación objetiva que al otro le plazca darle" (1993, p. 567; énfasis original). Al morir, la conciencia deja de poder oponerse a la mirada del Otro, a sus determinaciones, a sus interpretaciones. Incluso el olvido debe considerarse desde este punto de vista: "[s] er olvidado es ser objeto de una actitud del otro y de una decisión implícita del Prójimo. Ser olvidado es, en realidad, ser aprehendido resueltamente y para siempre como elemento fundido en una masa" (1993, pp. 564-565).

Entonces, si hemos insistido en la concepción sartreana de la muerte es porque ella ilumina este aspecto esencial de la realidad humana -también desatendido en gran parte por Heidegger-, y que la película de Kurosawa retrata en toda su significación y alcance, quizás sin proponérselo: la muerte es siempre para-otros. No en vano el film dedica más de un tercio de su duración a presentar, a través del recurso narrativo del flashback, las diversas interpretaciones de la vida y la muerte del protagonista, en su ausencia definitiva. Kurosawa había adelantado ese recurso en Rashōmon, la célebre producción de 1950 que introdujera su obra al público occidental. Sin embargo, en ese film se problematiza, ante todo, la cuestión de la verdad, la mentira, y el «perspectivismo», como algunos estudios han puesto de manifiesto con detalle (Grandío, 2010; Trakas, 2017). Los motivos últimos de los personajes de Rashōmon, y el curso de acontecimientos que efectivamente tuvo lugar -el «hecho bruto», para decirlo con Sartre- permanecen en penumbras al espectador. En Ikiru, por el contrario, al presentar el film en dos partes, una primera centrada en Watanabe, que finaliza con su proyecto de construcción del parque, y una segunda en que sus prójimos reconstruyen sus acciones, se revela el tema de la donación de sentido por parte de los otros en todo su alcance y, como si dijéramos, descarnadamente.

Desde esta perspectiva, se torna claro que lo que se pone en juego en las discusiones que tienen lugar en la ceremonia de despedida $-y$ ante la presencia inmutable de sus familiares, que confirman lo que Watanabe sospechaba cuando vivía, esto es, que les es indiferente-, son distintas interpretaciones sobre la vida del protagonista. Se trata, a un tiempo y en primer lugar, de interpretaciones sobre su muerte, y el modo en que ésta y su vida se interrelacionaron: ¿`sabía Watanabe de su enfermedad? 
¿A eso se debe su cambio de carácter, su impulso final, su vitalidad renovada? ¿O se debe, acaso, a su relación con Yoko, cuyos alcances permanecen opacos para sus allegados? ¿Tenía conciencia de que su muerte era inminente y por eso se dirigió al parque de Kuroe-Cho en una noche helada, a morir jugueteando en los columpios que había ayudado a construir para la comunidad de la que era parte, como una suerte de «abandono del creador en su obra»? ¿Significa esa muerte una silenciosa protesta contra la burocracia estatal, muerte destinada a ser tomada como ejemplo y reivindicada por los ciudadanos, una suerte de recordatorio del avasallamiento cotidiano y la instrumentalización de todo fenómeno por parte de la casta política? ¿O en verdad su significado reside, por así decirlo, en la «ausencia de todo significado», como parece querer el Primer Teniente de Alcalde, que responde a los periodistas con el argumento de la causalidad natural de la ciencia biológica?: "Watanabe padecía de un cáncer de estómago, murió a causa de una hemorragia interna» $-\mathrm{o}$, desde otro punto de vista: su muerte en el parque fue «casual», un mero azar; podría haber muerto esa misma noche, pero en su cama, o regresando a su hogar.

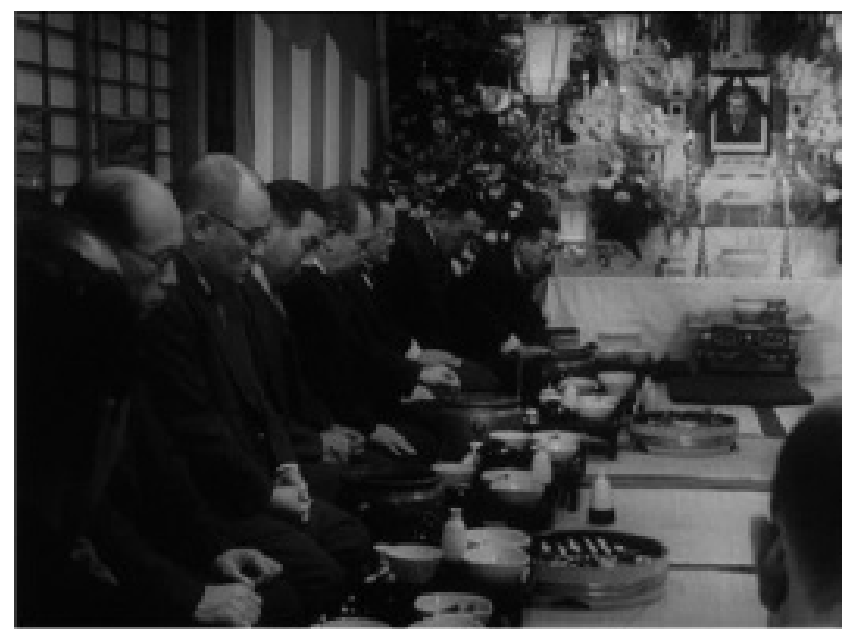

En definitiva, lo que el film de Kurosawa retrata es que, aún en el caso de que pudiésemos asumir nuestra propia muerte -una muerte con la que pretendemos «coronar» nuestra vida o, al menos, intentar redimirla en un último instante de grandeza, como es el caso de Watanabe-, nunca está dado a nosotros otorgar el sentido último de la órbita conclusa que es nuestra existencia. Mientras vivimos, podemos reinterpretar nuestro pasado y reorientarlo hacia nuevos posibles. Al morir, en cambio, nos hundimos bajo la mirada de los otros, esta vez definitivamente. Esa es la gran enseñanza de Sartre: "[e]star muerto es ser presa de los vivos" (1993, p. 566). Nuestra existencia, cerrada sobre sí misma, se presenta ahora ante los otros para ser escrutada, juzgada y valorada. Caeremos en el impiadoso olvido o seremos elegidos como héroes. Ninguna de las opciones está en nuestras manos.

\section{Coda. Sobre el «ser-con»}

El final del film es ambiguo. Tras presenciar las entusiastas palabras de los burócratas, que prometen seguir los pasos de Watanabe, el espectador observa la reiterada escena de la oficina, con su rutina, su automatismo, su gris. Quien ocupa el lugar de Watanabe, esto es, el nuevo Jefe de la Sección de Ciudadanos, recibe la notificación de que otra zona de Tokio está inundada. Como era de esperarse, automáticamente envía a quienes presentan la queja a la Sección de Obras Públicas. Repite, de ese modo, el gesto inicial del film: el «retraso de la decisión». Quien había sido el primero en reivindicar la responsabilidad de Watanabe en la construcción del parque ensaya un reproche, pero se arrepiente ante la mirada impasible del nuevo Jefe.

La película finaliza con un plano picado sobre el parque que Watanabe ha construido, y que varias familias disfrutan en una tarde de sol. Recordado por unos pocos, olvidado por otros, héroe anónimo de los más, Watanabe realizó, en sus últimos instantes, una vida resuelta hacia sus prójimos.

El tratamiento sartreano de la relación del para-sí con los otros reduce el nosotros-sujeto a una experiencia empírica, una "impresión puramente subjetiva" (1993, p. 449) que no alcanza a la estructura de la realidad humana. En ese sentido, Sartre critica a Heidegger en tanto y en cuanto éste habría colocado injustificadamente el «ser-con» [Mitsein] como una determinación ontológica, obviando todo análisis del ser-para, de lo que se ocupará largamente a partir de una indagación que tiene como hilo conductor la «mirada». Para Sartre, "la experiencia del nosotros-sujeto no tiene ningún valor de revelación metafísica; depende estrechamente de las diversas formas del para-otro y no es sino un enriquecimiento empírico de alguna de ellas" (1993, p. 451). El pensador francés agrega que "[a] esto, evidentemente, ha de atribuirse la extrema inestabilidad de tal experiencia” (1993, p. 451). El nosotros -ya el «Uno impersonal» [das Man], ya el «equipo», figuras que sintetizarían la perspectiva heideggeriana (1993, p. 274-5)- es tan sólo "una experiencia particular que se produce, en casos especiales, sobre el fundamento del ser-para-el-otro en general. El ser-para-el-otro precede y funda al ser-con-elotro" (1993, p. 438). En otras palabras, y sin juzgar sobre 
la interpretación sartreana de Heidegger -que, a nuestro juicio, se mueve indistintamente en los plano óntico y ontológico-, para el autor de El ser y la nada la relación esencial del para-sí con los otros es de oposición, antes que de solidaridad. El ser-con es tan sólo "una tregua provisional constituida en el seno del conflicto mismo", antes que "una solución definitiva del conflicto" (1993, p. 451). "La esencia de las relaciones entre conciencias no es el Mitsein, sino el conflicto" (1993, p. 452).

En el último apartado de El ser y la nada Sartre anuncia la elaboración de una Ética, que no llegará a escribir. La ontología, nos dice, "no puede formular de por sí prescripciones morales [] Deja entrever, sin embargo, lo que sería una ética que asumiera sus responsabilidades frente a una realidad bumana en situación" (1993, p. 646). Unos pocos años más tarde, en su famosa conferencia L'existentialisme est un humanisme [1946], Sartre dirá que "al querer la libertad descubrimos que depende enteramente de la libertad de los otros, y que la libertad de los otros depende de la nuestra", por lo cual "estoy obligado a querer, al mismo tiempo que mi libertad, la libertad de los otros" (1963, p. 39). Un autor contemporáneo de Sartre, Roger Garaudy (1964), ha notado cómo esa sentencia entraba en flagrante contradicción con la perspectiva existencialista previa, pues jerarquiza elecciones, proyectos. Asimismo, lo que el postulado sartreano -que trasunta, según Garaudy, un "brusco regreso a la moral de Kant"- expresa es que, en definitiva, las razones de vivir -el contenido del proyecto, el «valor»- deben encontrarse, ya no en uno mismo, sino en el Otro, en un
Prójimo que se recorta por fuera de la dialéctica trunca de la sujeción y la cosificación a partir de la mirada. Para Garaudy, es la experiencia de la resistencia al nazismo la que descubrió a Sartre esas posibilidades, que en definitiva son las de la historia. De hecho, buena parte del resto de la obra filosófica sartreana, signada por su viraje hacia el marxismo, intentará dar cuenta de relaciones humanas de un tipo distinto a las que plantea en El ser y la nada, que por esencia estaban, estas últimas, condenadas al fracaso.

En la escena final de Ikiru, en que se enfoca el parque de Kuroe-Cho, un grupo de niños corre, ríe, canta, baila, juega. Se balancea en los mismos columpios en que Watanabe exhaló sus últimos suspiros. «Allí donde hay niños, allí hay una Edad de Oro», recordamos con Novalis. El proyecto final de Watanabe ha interiorizado la alteridad, ha asumido la situación que hace de Watanabe un con-viviente y ha colocado el «valor» y la posibilidad de «salvación» en el Otro. El Otro del proyecto de Watanabe no es su prójimo en sentido estricto, con el que tendría una relación personal o un trato inter-individual, de tú a tú; es el Otro que se encuentra en el futuro, la colectividad humana en la que Watanabe ha nacido y a la que se entrega, en su acto postrero. La existencia individual se inserta, como una de sus posibilidades siempre abierta y arrojada al acaso, en el ciclo de continua renovación y trasformación -identidad en la diferencia- que es una comunidad que se asume como propia. En ello radica, más allá de todo olvido y anonimato, de todo absurdo, una esperanza última que puede polarizar nuestros esfuerzos, en la asunción de nuestra radical inmanencia y libertad.

\section{Referencias}

Bazin, A. (1977). El cine de la crueldad. Mensajero D.L.

Bovens, L. (1999). Authenticity in Kurosawa. The Journal of Value Inquiry, (33), 227-237.

Château, D. (2005). Sartre et le cinema. Séguier-Atlantica.

Churchill, S. (2012). “"Authentic Begin-towards-Death» as the Theme of Akira Kurosawa's (1952) film "Ikiru” " ger's (1927) Being and Time in Dialogue with Akira Kurosawa's film Ikiru”. Aarbus Heidegger Seminar, October 2, 2012 [inédito]. https://www.academia.edu/29841322/_Authentic_Begin-towards-Death_as_the_Theme_of_Akira_Kurosawa_s_1952_film_Ikiru_to_live_

Garaudy, R. (1964). Perspectivas del hombre. Existencialismo, pensamiento católico, marxismo. Editorial Platina. [1959].

Gordon, J. (1997). Kurosawa's existential masterpiece: A meditation on the meaning of life. Human Studies, 20, $137-151$.

Grandío, M. (2010). Tiempo y perspectiva en la película Rashōmon de Akira Kurosawa. Vivat Academia, (111). http://www.ucm.es/ info/vivataca/numeros/n111/Articulos111.pdf

Kaufmann, W. (1956). Existentialism. From Dostoiersky to Sartre. Meridian Books.

Kurosawa, A. (director), Jingo, M. (productor), (1950). Rashōmon [Película]. Daiei Film.

Kurosawa, A. (director), Sōjirō M. (productor), (1952). Ikiru [Vivir] [Película]. Toho.

Kurosawa, A. (1983). Something Like an Autobiography. Vintage Books. [Trad.: Audie E. Bock]. 
Nietzsche, F. (1979). Así habló Zaratustra. Alianza. [Trad. Andrés Sánchez Pascual]. [1885].

Prince, S. (1991). The Warrior's Camera: The cinema of Akira Kurosawa. Princeton University Press.

Richie, D. (1970) The films of Akira Kurosawa. University of California Press.

Sartre, J. P. (1993). El ser y la nada. Altaya. [Trad.: Juan Valmar]. [1943].

Sartre, J. P. (1963). “El existencialismo es un humanismo”. En Existencialismo y humanismo. Sur. [1946].

Tolstoi, L. (2013). La muerte de Iván Ilich. Losada. [1886].

Trakas, M. (2017). Rashōmon. La memoria y su conexión con el pasado. Ética y Cine Journal, 7(3), 11-21.

1 La bibliografía en torno al tema es vasta. Para una introducción canónica, cf. Kaufmann (1956).

2 Para un trabajo que aborda la relación de Sartre con el cine desde sus múltiples perspectivas, cf. Château (2005).

3 There is nothing that says more about its creator than the work itself.

4 Sartre la analiza junto a otras dos formas, de las que no me ocuparé: por un lado, el "concepto metaestable de «trascendencia-facticidad»" (1993, p. 91), por el cual el para-sí afirma "la identidad de ambos conservándoles sus diferencias”, de modo tal "que se pueda, en el instante en que se capta la una, encontrarse bruscamente frente a la otra” (p. 90); y, por otro, el hecho de que la conciencia es ser-para-otro, lo que "permite una síntesis perpetuamente en disgregación y un juego de evasión perpetua del para-sí al para-otro y del para-otro al para-sí” (p. 92). 